\title{
Reconstruction wide-aperture GPR data through binning and interpolation: a case study in Marambaia barrier island
}

\author{
Martins, S.S ${ }^{* 1,4}$; Gomes, E.N.S ${ }^{2,5}$; Travassos, J.M ${ }^{3,4}$; Mansur, W.J ${ }^{3}$ \\ ${ }^{1}$ DPG-UFRRJ, ${ }^{2}$ PGG-UFPA, ${ }^{3}$ COPPE-UFRJ, ${ }^{4}$ INCT da Criosfera/CNPq, ${ }^{5}$ INCT-GP/CNPq
}

Copyright 2018, SBGf - Sociedade Brasileira de Geofísica

Este texto foi preparado para a apresentação no VIII Simpósio Brasileiro de Geofísica, Salinópolis, 18 a 20 de setembro de 2018. Seu conteúdo foi revisado pelo Comitê Técnico do VIII SimBGf, mas não necessariamente representa a opinião da SBGf ou de seus associados. É proibida a reprodução total ou parcial deste material para propósitos comerciais sem prévia autorização da SBGf.

\begin{abstract}
In this work, several fixed-offset GPR data was acquired in Marambaia barrier island. These data are processed to simulate multi-channels acquisition and thus allow the estimation of the 2-D velocity model in time of the subsurface area data. The imaging data obtained from these reflectors focused best shown with greater number of refractions being collapsed, when compared with the imaging obtained in conventional manner GPR data, which is used $1-D$ velocity model.
\end{abstract}

\section{Introduction}

Most of the data acquisition in GPR (Ground Penetrating Radar) is done along fixed-offset profiles, where velocity is estimated only at a few isolated points in the survey area, at the locations of variable offset gathers such as a CMP (Common Midpoint) are available.

The estimation of velocity variations within a given area is usually done resorting to a limited number of CMP gathers yielding 1-D velocity models, valid only at the center of those gathers. It is usual to extrapolate those velocity models throughout the whole survey area. Obviously the $1-D$ velocity models may yield depth estimates calibrated only at the few available points within the survey area. This is obviously an important limiting factor in estimating the true reflector structure in the subsurface.

A 2-D velocity model for the whole surveyed area can be produced for the case of a multi-channel GPR data, a practical challenge with a GPR equipment intended for geological targets, usually mono channel. Here we resort to trace interpolation in order to simulate multi-channel data from several collinear fixed-offset GPR profiles (Martins and Travassos, 2015) and construct a 2-D velocity model for whole profile.

Field strategies leading to the acquisition of multi-offset gathers are anything but new (Fisher et al., 1992; Pipan et al., 1999; Leparoux et al., 2001; Baradello et al., 2005; Grasmueck et al., 2005; Bradford, 2008; Gerhards et al., 2008; Bradford et al., 2009). In general terms multi-offset gathers are either acquired directly or assembled during processing from distinct collinear fixedoffset profiles. Either collected directly as multi-offset gathers or assembled from several collinear profiles one must have a dense spatial sampling to keep spatial alias at bail.
In this work we resort to a dual methodology encompassing a field strategy of collecting distinct collinear fixed-offset profiles associated to trace interpolation to un-alias so constructed multi-offset gathers Martins and Travassos (2015). The interpolation used here is based on adaptive prediction-error filtering (PEF) and regularized nonstationary autoregression (Liu and Fomel, 2011). Theory predicts that non-stationary time and space domain PEFs may be used to interpolate aliased sections, inserting new traces between those originally recorded.

\section{Regional Geology}

Sepetiba bay is part of great sandspit from south of Rio de Janeiro (Brazil province) between $22^{\circ} 53^{\prime}-23^{\circ} 05^{\prime} S$ and $44^{\circ} 01^{\prime}-43^{\circ} 33^{\prime} \mathrm{W}$. Has around $500 \mathrm{~km}^{2}$ in area, is delimited by formation in North by Mar ridge, Northeast by Madureira barrier island, Northwest by Pedra Branca ridge and South by Marambaia barrier island. On East, next no Guaratiba, the bay is linked to the open sea by a thin canal, on West the bay has a great canal surround by island chains that limit the Marambaia barrier island Roncarati and Carelli (2012). The coastlines complex of Sepetiba bay are involved those elements: a lagoon (Sepetiba bay), a delta dominated by river processes, a estuary of Cação river, a flatland cover by mangrove and island of Marambaia barrier island Roncarati and Carelli (2012).

Marambaia barrier island works as a breakwater, separating lagoon and marine environments and isolating the bay water from the sea. The length is around 40 kilometer and the thickness varying from 50 meters (at central part) to 50 kilometer (at extremity)Carelli et al. (2012). The Cenozoic geological evolution of the Marambaia barrier Island was recently reviewed by Carelli et al. (2012) has seven evolutionary stages conditioned by transgression, when the rate of sea level rise overcomes the amount inshore sediment supply, and progradation, when sediments are pushed on shore: (1) Formation of the internal of barrier along two parallel sand bars; (2) Completion of the internal part of barrier; beginning of the buildup of the external part; (3) Completion of the whole barrier; (4) Formation of lagoons between the internal and external parts; (5) Erosion of the external and internal parts of barrier, with the total disappearance of the former; (6) Reconstructions of the whole barrier, preserving the lagoons closer to Marambaia Island and (7) Partial erosion of the internal part of the barrier.

\section{Data Acquisition}

This work was done on the East part of Marambaia barrier island at $23.05^{\circ} \mathrm{S}, 43.58^{\circ} \mathrm{W}$ on a sand trail marked as show on the Figure 1. The acquisitions were done on S-N direction, in other words, starting closer the sea 


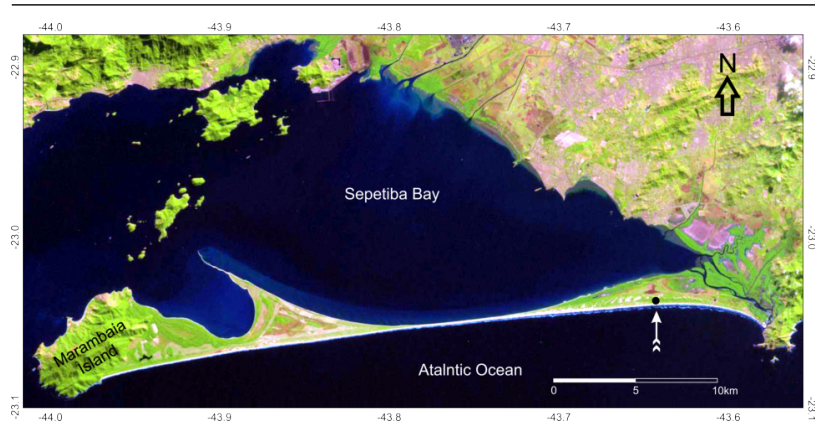

Figure 1: Geological map of the Marambaia barrier island and its vicinity. Sediments from the Quaternary (Q) are shown in yellow, all the other geological mapped units are granitic or rhyolitic rocks. The location of the profile is marked with a black solid dot.

and finishing closer to the bay. The equipment used to collect the data was a Pulse Ekko bistatic unshielded GPR with $100 \mathrm{MHz}$ of central frequency and two differential GPS (Base and Rover). The equipment was mounted on three sledges carrying the rover GPS, the transmitting and the receiving antennae, respectively. The acquisition configuration of the antennae was broadside perpendicular and the base GPS was mounted near of the line acquisition to obtain the post-positioning processed. The local base GPS was referenced to another base GPS near of center of Rio de Janeiro; this configuration the post-processed positioning accuracy of the rover GPS around $0.05 \mathrm{~m}$.

The acquisition was done using fixed-offset configuration; the profile was repeated seven times increasing the separation between transmitter and receiver antennae following this configuration: 1, 1.9, 3.1, 3.9, 6.4, 6.8 and $9.2 \mathrm{~m}$. The data was collected on free running mode, consequently, each profile has different number of traces varying from 548 to 860 and the time window of $500 \mathrm{~ns}$. We also collected one CMP profile at the center of the line acquisition; this CMP was done in order to obtain a $1-D$ velocity model and as a quality control for $2-D$ velocity model.

\section{Processing Data}

\section{Coalescing Fixed-Offset into Multi-Offset gathers}

A GPR multi-offset data, usually to be very time consuming to be acquired, especially when dealing with equipment of a couple of channel. One way to construct a multi-offset is using a equipment with a couple of channel and merge several fixed-offset on a unique data. At this work, we will follow a similar procedure described at the Literature of Martins and Travassos (2015).

The proceeding to merge several fixed-offsets into a multioffset file is binning the source position that falling in a square bin with size of $0.5 \times 4.0 \mathrm{~m}$ The square bin is follow a trail constructed by barycenter of seven profiles and travel with $0.3 \mathrm{~m}$ step increment Figure 2. For each bin, should fall sources of seven profiles, in some cases more them one source (same offset) fall into the bin, in this case, we stacked the traces with same offset in order to increasing the signal-to-noise ratio.

Finally, was discarded 25 profiles from the beginning

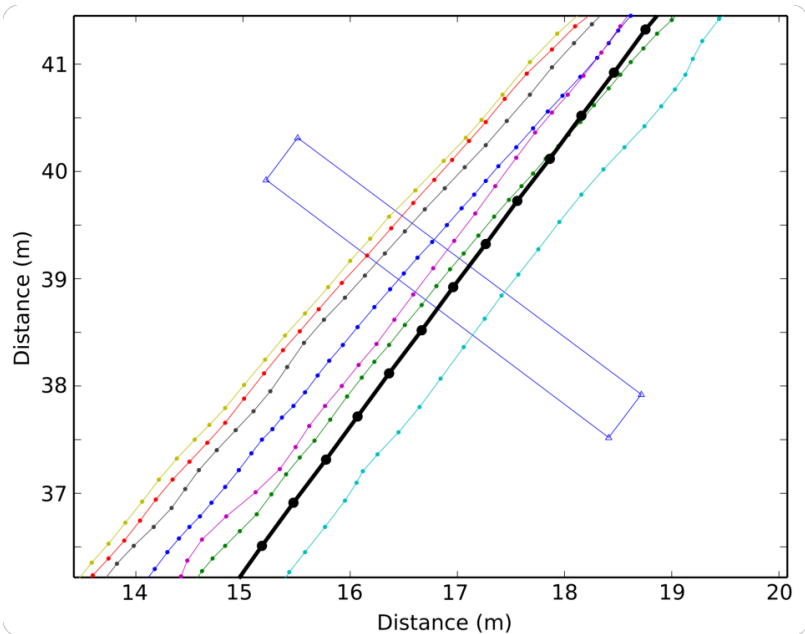

Figure 2: Detail of the survey, the thin lines presents the fixed-offset acquisition, the dots represent the source position; the thick line present the rail position where the bin travel, the black dots is the center of the bins and the rectangle is the bin.
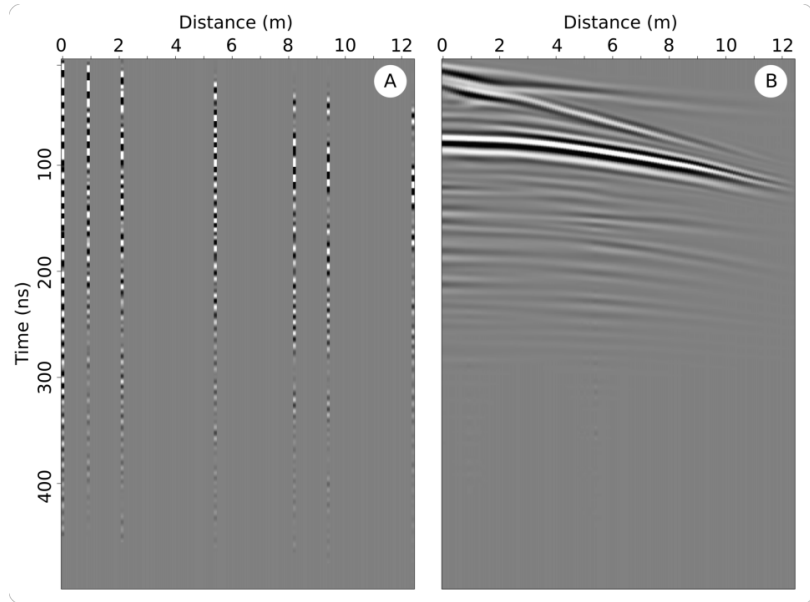

Figure 3: The panel A shows a alias Common shot and the panel $B$ shows the result after interpolation alias free.

and the end, due those bins does not have fall seven sources with same offset fallen. The multi-offset data was composed by 472 common-shots with $0.3 \mathrm{~m}$ step increment and each common-shot has with 7 traces each.

\section{Interpolate Common-Shot alias}

Each common-shot have only 7 traces in a section over $9.2 \mathrm{~m}$, in other words, our data have a heavily alias demanding a interpolation. To interpolate the data we will use the algorithm of Liu and Fomel (2011) and follow the steps-by-step to how use the algorithm can be found on work of Martins and Travassos (2015).

The Figure $3 \mathrm{~A}$ is a example one common-shot from the multi-offset data. Note on the Figure that we fill up with zeroed traces between real traces. The reason for that become the fact the algorithm need to regularize the data before interpolate, it mean, all the traces has the same distance increment. 


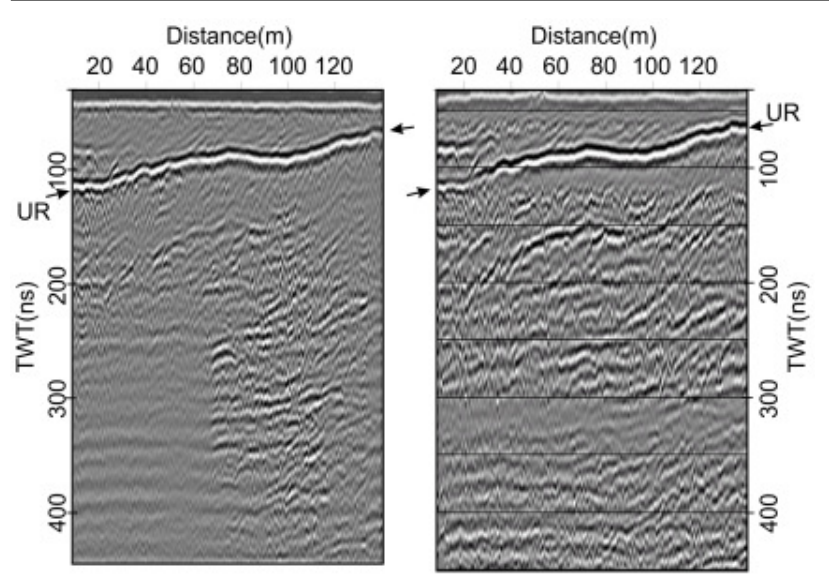

Figure 4: Left and right panels show Fixed-offset of fieldwork and Fixed-offset interpolated, respectively. The arrows point to the beginning and end of the unconformity UR.

The result of interpolated common-shot can be seen on the Figure 3B, now we have a data free alias, we increase significantly the number of traces for each common-offset, consequently increase the fold number. Now the multioffset data has $274 \times 125$ totalizing 30875 traces.

Another improvement of the interpolation is the quality of the fixed-offset. On the Figure 4 can be seen two different fixed-offset from first offsets. On the left hand side in the fixed-offset from fieldwork $\left(\mathrm{FO}_{\mathrm{f}}\right)$ and right hand side after interpolation $\left(\mathrm{FO}_{\mathrm{i}}\right)$. Is clear the improvement the quality of the interpolated $\mathrm{FO}$. $\mathrm{FO}_{\mathrm{i}}$ section has a better signal-tonoise $\mathrm{S} / \mathrm{N}$ and its deep reflector is more rich in detail than $\mathrm{FO}_{f}$. On $\mathrm{FO}_{f}$, it is important to mention a region between 0-70 meters and below 250ns, this region suffer a highlight, suggest this part of radargram was strongly contaminated by noise, this noise was attenuated on $\mathrm{FO}_{i}$ section.

\section{Results}

With the interpolated data sorted in CS gathers we can go through both post and pre-stack processing. On this step of the work, we apply the conventional seismic processing on data following this sequence: (1) sorting Common-Shot into Common-Mid Point, (2) semblance analysis for each CMP, (3) picking velocity for each semblance, (4) Normal Moveout correction and (5) stacked section. The steps 2 and 3 was done automatically using a algorithm of Fomel (2009), the result of this processing can be seeing on the Figure 5

Figure 5 shows the 1-D and the 2-D velocity models, $V_{r m s}$ estimated through velocity analysis on the central CMP and on the super gathers mentioned above. $v_{r m s}$ has a 2-D behavior manifested by the tendency of the lower velocities in reaching earlier times with increasing distances. Obviously as it is an 1-D model valid only such behavior cannot be reproduced by $v_{r m s}$ at the central point of the CMP gather. Notwithstanding $v_{r m s}$ is a smoothed model while $v_{r m s}$ is not it is easy to see the latter $s$ even unable to reproduce the velocity distribution at the center of the profile, where it is located.

Figure 5 also shows the result of a Kirchhoff migration

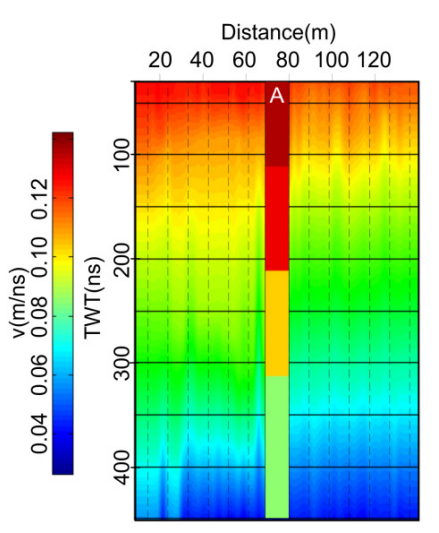

Distance $(m)$

$20 \quad 40 \quad 60 \quad 80 \quad 100120$

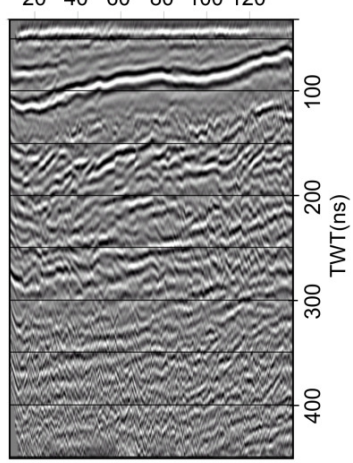

Figure 5: Left panel shows $v_{r m s}$, having $v_{r m s}$ superimposed on it, marked with the letter A by velocity from CMP. The right panel shows the result of a Kirchhoff migration, using $v_{\mathrm{rms}}$ model, on the stacked section.

on the stacked, zero offset, section. It is easy to see a great improvement as compared to the two non-migrated FO sections, shown in Figure 4 . Most reflectors now appear clearer and stronger, yielding a sharper picture of the subsurface and reaching later times, after 350ns. On the other hand the sloping depositional reflectors which appeared clearly in sections $\mathrm{FO}_{f}$ and $\mathrm{FO}_{i}$ above reflector UR, do not show the section any longer.

\section{Conclusions}

On this work was discuss a feasible way to construct a multi-offset GPR data from fixed offset data. The fixedoffset data acquisition use to be faster than multi-offset acquisition. However, the way it was proposed here, require a preprocessing to set the new data. Briefly, we stack several source fallen in a square bin to produce a common-shots, then we construct a multi-offset data.

The result from transform fixed-offset into multi-offset by itself is better then a simple fixed-offset, there are some reason for this, one became the fact the sources was stacked into one super source consequently increasing the reason signal-to-noise.

The data interpolation was an important step of the work. On this stage we reconstruct a alias multi-offset data into a data alias free and more important, the interpolated data allowed build up a 2-d velocity model and consequently obtain a stacked and migrated section.

Also, was showed three different Zero-offset sections, the first one was the fixed-offset by fieldwork $\mathrm{FO}_{f}$, second was first offset from interpolated data $\mathrm{FO}_{i}$ and third section was Stacked and Migrated data (SM). It is clear to see the evolution of image quality in each stage, that was only possible due all the proceeding described at this abstract.

\section{Acknowledgments}

We would like to thanks the UFRRJ, UFPA and UFRJ for the structure offered to realize the work. All the authors thanks to INCT da Criosfera and INCT-PG to support the work. 


\section{References}

Baradello, L., J. M. Carcione, and D. N. Yabar, 2005, Multi-offset GPR surveys for complex targets: Presented at the 9th International Congress of the Brazilian Geophysical Society.

Bradford, J. H., 2008, Measuring water content heterogeneity using multifold GPR with reflection tomography: Vadose Zone Journal, 7, 184-193.

Bradford, J. H., J. Nichols, T. D. Mikesell, and J. T. Harper, 2009, Continuous profiles of electromagnetic wave velocity and water content in glaciers: an example from bench glacier, alaska, USA: Annals of Glaciology, 50, 1-9.

Carelli, S. G., P. L. F. Rocha, and H. Roncarati, 2012, Evolução holocênica da planície costeira de itaguaí, baía de sepetiba/rj baseado em evidências geológicas, geocronológicas e geofísicas: Baía de Sepetiba: Estado da Arte, Chapter 4, 85-102.

Fisher, E., G. A. McMechan, and A. P. Annan, 1992, Acquisition and processing of wide-aperture groundpenetrating radar data: Geophysics, 57, 495-504.

Fomel, S., 2009, Velocity analysis using AB semblance: Geophysical Prospecting, 57, 311-321.

Gerhards, H., U. Wollschläger, Q. Yu, P. Schiwek, X. Pan, and K. Roth, 2008, Continuous and simultaneous measurement of reflector depth and average soil-water content with multichannel ground-penetrating radar: Geophysics, 73, J15-J23.

Grasmueck, M., R. Weger, and H. Horstmeyer, 2005, Fullresolution 3D GPR imaging: Geophysics, 70, K12-K19.

Leparoux, D., D. Gibert, and P. Côte, 2001, Adaptation of prestack migration to multi-offset ground-penetrating radar (GPR) data: Geophysical Prospecting, 49, 374386.

Liu, Y., and S. Fomel, 2011, Seismic data interpolation beyond aliasing using regularized nonstationary autoregression: Geophysics, 76, V69-V77.

Martins, S. S., and J. M. Travassos, 2015, Interpolating wide-aperture ground-penetrating radar beyond aliasing: Geophysics, 80, H13-H22.

Pipan, M., L. Baradello, E. Forte, A. Prizzon, and I. Finetti, 1999, 2-d and 3-d processing and interpretation of multifold ground penetrating radar data: a case history from an archaeological site: Journal of Applied Geophysics, 41, 271-292.

Roncarati, H., and S. G. Carelli, 2012, Considerações sobre o estado da arte dos processos geológicos cenozóicos atuantes na baía de sepetiba: Baía de Sepetiba: Estado da Arte, Chapter 2, 13-36. 